Original Article

\title{
FORMULATION AND IN-VITRO EVALUATION OF THEOPHYLLINE HYDROCHLORIDE EFFERVESCENT FLOATING TABLETS: EFFECT OF POLYMER CONCENTRATION ON TABLET BUOYANCY
}

\author{
AKPABIO E. I. ${ }^{1 *}$, EFFIONG D. E. ${ }^{1}$, UWAH T. 0. ${ }^{1}$, SUNDAY N. I. ${ }^{2}$ \\ 1Pharmaceutics and Pharmaceutical Technology Department, Faculty of Pharmacy, University of Uyo, Nigeria, ${ }^{2}$ National Institute for \\ Pharmaceutical Research and Development (NIPRD) Garki, Abuja, Nigeria \\ Email: pharmeka2000@yahoo.com
}

Received: 23 Jul 2019, Revised and Accepted: 29 Nov 2019

\begin{abstract}
Objective: This study was undertaken to formulate a floating drug delivery system of theophylline hydrochloride using different concentrations of a chosen polymer and then investigate how polymer concentration affects buoyancy and drug release properties of the tablets.

Methods: Hydroxypropyl methylcellulose (HPMC) at different concentration levels of 15\% (F1), 20\% (F2) and 30\% (F3) was used to form the three formulation batches of floating tablets. Wet granulation method was used for the granule preparation while Sodium bicarbonate and citric acid were used as the gas generating agent. The physical properties of the granules and the floating tablets were evaluated. Also determined were the physicomechanical properties, buoyancy and swelling characteristics of the tablets. The in vitro drug release study was carried out according to the USP I (basket method) for $8 \mathrm{~h}$ in $900 \mathrm{ml} 0.1 \mathrm{~N} \mathrm{HCl}$ at $50 \mathrm{rpm}$. Samples withdrawn at the regular predetermined time were analyzed spectrophotometrically at a wavelength of $271 \mathrm{~nm}$ and data obtained statistically analyzed by one-way analysis of variance (ANOVA). The differences between means were considered significant at $\mathrm{P}<0.05$.
\end{abstract}

Results: The result showed that polymer (HPMC) concentration significantly ( $p>0.05)$ increased swelling index and improved floating lag time, it had no significant effect on the total floating time. Percentage drug release at the end of $8 \mathrm{~h}$ was $100 \%$, 98.2\% and 96.13\% for formulation F1, F2 and F3, respectively. All three formulations followed the Higuchi drug release kinetics model and the mechanism of drug release was the non Fickian diffusion with exponents of $0.46,0.51$ and 0.56 for the respective batch.

Conclusion: Batch F3 gave a better-controlled drug release and floating properties in comparison to batch F1 and F2 thus Polymer concentration influenced the onset of floating and controlled the release of Theophylline.

Keywords: Theophylline, Buoyancy, Swelling index, Floating tablets, Gastric residence time

(C) 2020 The Authors. Published by Innovare Academic Sciences Pvt Ltd. This is an open-access article under the CC BY license (http://creativecommons.org/licenses/by/4.0/) DOI: http://dx.doi.org/10.22159/ijpps.2020v12i1.35055. Journal homepage: https://innovareacademics.in/journals/index.php/ijpps

\section{INTRODUCTION}

Oral delivery is the most popular route of drug administration due to its versatility, ease of administration and patient compliance [1]. Drugs with short half-lives and that are easily absorbed from the gastrointestinal tract (GIT) are, however, eliminated quickly from systemic circulation after oral administration. To achieve and maintain the concentration of these types of drugs within the effective therapeutic range, it is often necessary to frequently administer the drug with resultant fluctuation levels in the plasma [2]. To avoid this limitation, the development of oral modified (sustained) release formulations is an attempt to release the drug slowly into the gastrointestinal tract and maintain an effective drug concentration in systemic circulation for a long time [3].

After oral administration, sustained release dosage forms are retained in the gastrointestinal tract, releasing the drug in a controlled manner, so that its absorption sites in the tract are continuously supplied. These drug delivery systems nevertheless suffer mainly from two physiological events: (i) the unpredictable short gastric emptying time and (ii) the brief gastric retention time. These can result in incomplete drug release from the dosage form in the absorption region (stomach or upper part of the small intestine), leading to diminished efficacy of administered dose [3]. Gastric emptying of dosage forms is an extremely variable process, thus being able to influence the emptying time can be a valuable asset for dosage forms that can reside in the stomach for a longer period of time than the conventional ones [4]. Many studies have been performed on gastro retentive delivery, an approach to achieve sustained release dosage forms of drugs having prolonged gastric residence time and this technique helps to improve site-specific targeting, increased solubility, better absorption and overall bioavailability of some poorly soluble of drugs such as theophylline, domperidone [5].

Theophylline is a methylxanthine derivative that is very effective in the treatment of chronic bronchial asthma and bronchospastic reaction. It has a narrow therapeutic concentration range (from 10$20 \mu \mathrm{g} / \mathrm{ml}$ ) with a short half-life, which necessitates frequent dosing with conventional dosage forms [6].<smiles>Cn1c(=O)c2[nH]cnc2n(C)c1=O</smiles>

Fig. 1: Chemical structure of theophylline

The toxicity of theophylline usually appears at a concentration above $20 \mu \mathrm{g} / \mathrm{ml}$ and the fluctuations in its serum concentration can result in variability in the clinical response. Therefore, there is an obvious therapeutic need for a sustained release dosage form of theophylline, which will be able to maintain its therapeutic serum levels throughout $24 \mathrm{~h}$ following a once or twice daily dose administration [7].

Although several works have formulated theophylline floating delivery, many as directly compressible tablets, capsules, microbeads and as suspension, this original work was aimed at preparing sustained release effervescent floating tablet matrix of theophylline after wet granulation method and then determine the effect of HPMC concentration on ideal buoyancy and drug release $[6,8,9]$. 


\section{MATERIALS AND METHODS}

\section{Materials}

Anhydrous Theophylline hydrochloride was purchased as a pure drug from Sigma-Aldrich, UK. Other excipients used were: HPMC (Hopkins and Williams Ltd, Stanheat Essex, England), Sodium bicarbonate, Stearic acid (BDH chemicals Poole, England) and citric acid (Philip Harris Ltd, Shenstone, England), magnesium stearate and talc obtained from (Shermen chemical Ltd, Sunderland and Sandy, England). Also, 95 \% ethanol (Analar grade) was used.

\section{Method}

\section{Preparation of granules}

The granules were prepared using the wet granulation method. Three batches of granules were prepared using the different concentrations of HPMC as the polymer. Batch 1 consisted of $10 \%$ polymer concentration (F1), a second batch (F2) and a third one (F3) consisted of $20 \%$ and $30 \%$ polymer concentration respectively. For batch 1 the ingredients (theophylline, sodium bicarbonate and citric acid) were weighed accurately and thoroughly mixed in a porcelain mortar. Granulation was done with a mixture of required HPMC in $95 \%$ ethanol added to the powder mix in the mortar to form a wet mass. The wet mass was passed through a $2 \mathrm{~mm}$ sieve and the resulting granules dried in a conventional hot air oven
(Techmel and Techmel, USA) at $60^{\circ} \mathrm{C}$ for $2 \mathrm{~h}$. The dried granules were then passed through a $1 \mathrm{~mm}$ sieve to obtain finer granules of uniform size. The same procedure was repeated for batch 2 and 3.

\section{Evaluation of theophylline granules \\ Flow rate and angle of repose}

Angle of repose was determined using the fixed funnel method. A clean dry funnel was kept upright in a retort stand at a height $10 \mathrm{~cm}$ above a paper placed in a flat horizontal surface. The aperture of the funnel was blocked and $10 \mathrm{~g}$ of powder sample was poured into the funnel. Then the funnel was opened to release the powder onto the paper to form a conical heap. The height of the heap was measured by using a ruler and the diameter of the cone was also measured. The experiment was repeated three times for each batch of granules and the average was calculated. Angle of repose was calculated by using the equation (1). The flow rate of the granules was determined by recording the time taken for the $10 \mathrm{~g}$ of granules from each batch to flow through the fixed funnel suspended from the retort stand. Triplicate values were determined.

$$
\operatorname{Tan} \theta=\frac{h}{r}
$$

Where;

$h$-height of heap and $r$-radius of the base of the powder

Table 1: Composition of theophylline floating tablet

\begin{tabular}{|c|c|c|c|}
\hline Ingredients & F1 & F2 & F3 \\
\hline Theophylline (mg) & 200 & 200 & 200 \\
\hline HPMC $(\%)$ & 15 & 20 & 30 \\
\hline Sodium bicarbonate (\%) & 10 & 10 & 10 \\
\hline Citric acid (\%) & 5 & 5 & 5 \\
\hline Stearic acid (\%) & 5 & 5 & 5 \\
\hline Magnesium Stearate (\%) & 1 & 1 & 1 \\
\hline Talc (\%) & 1 & 1 & 1 \\
\hline
\end{tabular}

\section{Bulk and tapped density}

A 10 g quantity of the granules was weighed and transferred into a $100 \mathrm{ml}$ graduated cylinder. The initial volume $\mathrm{V}$ was noted. The cylinder was mechanically tapped until no further reduction in volume was observed. The new volume $V_{1}$ was noted. This determination was done in triplicate for each batch of granules and the average was calculated. The bulk and tapped densities were calculated using the equations below:

$$
\begin{aligned}
& \left.\boldsymbol{B d}=\frac{\boldsymbol{w}}{v} \ldots \ldots \ldots \ldots \ldots . . . . . .2\right) \text { and } \\
& \boldsymbol{T d}=\frac{w}{v 1}
\end{aligned}
$$

Where $B d$ is bulk density, $T d$ the tapped density, $W$ is the weight of granule and $V$ is bulk volume and is the tapped volumeV $V_{1}$.

\section{Hausner's ratio and carr's compressibility index}

These values were calculated as the ratios given below for each batch of granules.

$$
\begin{gathered}
\text { Hausner ratio }=\frac{T d}{B d} \\
\text { Carr's } \text { index }=\frac{T d-B d}{T d} \times 100 . .
\end{gathered}
$$

Where $T d=$ of granules and $B d=$ of granule

\section{Determination of granule density}

The fluid displacement method using a pycnometer was used. A 25 $\mathrm{ml}$ pycnometer was weighed and the weight was noted, thereafter the pycnometer bottle was filled with xylene and the excess was wiped off. The filled bottle was reweighed, and the difference between this new weight and the weight of the empty pycnometer bottle was calculated. A $1 \mathrm{~g}$ quantity of each batch of granule was transferred into the pycnometer bottle. The excess xylene was wiped off and the bottle was weighed again. The granule density was then calculated using the equation below.
Granule density $(G d)=\frac{d s(W s)}{W s-(W 2-W 1)}$

Where,

Ds is the density of non-solvent (Xylene), $\mathrm{W}_{\mathrm{s}}$ is the weight of granule sample, $W_{1}$ is the weight of pycnometer+solvent and $W_{2}$ is the weight of pycnometer+sample+solvent

\section{Granule porosity and packing fraction of the granules}

The porosity and packing fraction of each batch of granules were determined using the equations below:

$$
\begin{aligned}
& \text { Packing fraction }(P f)=\frac{B d}{G d} \ldots \ldots \\
& \text { Granule porosity }=[1-P f]
\end{aligned}
$$

\section{Compression of theophylline tablets}

The prepared granules were lubricated with $5 \%$ stearic acid, $1 \%$ magnesium stearate and $1 \%$ talc, and compressed into tablets using a single punch tableting press fitted with $12.5 \mathrm{~mm}$ flat-faced punches (Cadmach, India) at a constant compression force of $15 \mathrm{kN}$.

\section{Evaluation of theophylline floating tablets}

\section{Weight uniformity test}

Twenty (20) tablets were randomly selected from each batch and individually weighed using an electronic balance (Ohaus, Galaxy). The mean, standard deviation and coefficient of variation were calculated.

\section{Crushing strength and friability}

The crushing strength of the tablets was determined using the Monsanto hardness tester (Rolex, Chandigarh). Ten tablets from each batch were randomly selected and tested and the average calculated. The friability of 5 tablets was measured in a Roche friability apparatus (UNID 056830 Campbell Electronic, Mumbai, 
India). The tablets were dusted and weighed ( $\mathrm{W}_{\mathrm{o}}$ ) and before being placed in the friabilator, which was then operated at a speed of 25 rpm for $4 \mathrm{~min}$. Then the tablets were removed from the chamber dusted and reweighed $\left(W_{1}\right)$. The friability was then calculated using the equation below:

$$
\text { Friabiliity }=\left[\mathbf{1}-\frac{W \mathbf{1}}{W \mathbf{0}}\right] \times \mathbf{1 0 0}
$$

Where, $W_{0}$ is the initial weight of tablets before the test, $W_{1}$ is the final weight of tablets after the test.

\section{Thickness and diameter}

The thickness of each of 10 randomly selected tablets was determined using the micrometer screw gauge (KFW Scientific Industries Ambala Cantt, India) and the average thickness was calculated.

The diameter of each of 10 tablets from each batch was randomly selected and their individual diameter was determined using the micrometer screw gauge (KFW Scientific Industries Ambala Cantt, India) and the average diameter was calculated.

Tablet porosity: The tablet porosity was calculated using the Equation below;

$$
\text { Tablet porosity }(\varepsilon)=\left[1-\frac{m}{\rho \pi r^{2} 2 h}\right] \times 100
$$

Where $m$ is mean weight of tablets, $\rho$ is particle density, $r$ is mean tablet radius and $\mathrm{h}$ is tablet thickness.

\section{Swelling index}

One tablet from each batch was weighed before placing them in a Petri dish containing $0.1 \mathrm{~N} \mathrm{HCl}$. At 30 minute intervals, the swollen tablets were taken out and weighed after mopping off the fluid medium from the swollen tablets using a blotting paper. The swelling index of the tablet was then calculated using the equation below:

$$
S I=\left[\frac{W t-W 0}{W 0}\right] \times 100
$$

Where, SI-swelling index, $\mathrm{W}_{\mathrm{t}}$-weight of tablet at time $\mathrm{t}, \mathrm{W}_{0}$-initial weight of the tablet

\section{In vitro buoyancy studies}

One tablet from each formulation was placed in $250 \mathrm{ml}$ beaker containing $0.1 \mathrm{~N} \mathrm{HCl}$. The time taken by the tablet to move from the bottom of the beaker to the top and float was noted and recorded as the floating lag time. The time for which the tablet remained floating on the surface was noted and recorded as the total floating time. The determination was carried out in triplicates and the average calculated.

\section{Standard calibration curve of theophylline in $0.1 \mathrm{~N} \mathrm{HCl}$}

A $50 \mathrm{mg}$ quantity of theophylline powder was dissolved in $30 \mathrm{ml}$ of $0.1 \mathrm{~N} \mathrm{HCl}$. The resultant solution was transferred to $50 \mathrm{ml}$ volumetric flask and made up to volume with $0.1 \mathrm{~N} \mathrm{HCl}$. Serial dilutions of 2 $\mu \mathrm{g} / \mathrm{ml}, 4 \mu \mathrm{g} / \mathrm{ml}, 6 \mu \mathrm{g} / \mathrm{ml}, 8 \mu \mathrm{g} / \mathrm{ml}, 10 \mu \mathrm{g} / \mathrm{ml}$ and $12 \mu \mathrm{g} / \mathrm{ml}$ were prepared, and their absorbances were read in a UVspectrophotometer (UNICO-spectrophotometer, UV-2100 PC, Shanghai Instrument Co., China) at a wavelength of $271 \mathrm{~nm}$. Graphs of absorbance versus concentration were plotted to obtain the calibration curves of theophylline in $0.1 \mathrm{~N} \mathrm{HCl}$.

\section{Absolute drug content of theophylline tablets}

Ten pre-weighed tablets from each batch were crushed in a mortar. A powdered quantity equivalent to $200 \mathrm{mg}$ was weighed out and dissolved in $100 \mathrm{ml}$ of $0.1 \mathrm{~N} \mathrm{HCl}$ in a volumetric flask. The solution was filtered using a Whatman filter paper no.2, $0.1 \mathrm{ml}$ of the filtrate was then measured and diluted up to $10 \mathrm{ml}$ with $0.1 \mathrm{~N} \mathrm{HCl}$ and analyzed spectrophotometrically at $271 \mathrm{~nm}$ using $0.1 \mathrm{~N} \mathrm{HCl}$ as blank. The concentration of theophylline was then obtained by using the standard calibration curve of theophylline.

\section{In vitro drug release study of theophylline floating tablets}

Drug release study was carried out according to USP I (basket) method. The dissolution studies were conducted with dissolution apparatus (RCZ-6C3, China). The dissolution medium was $900 \mathrm{ml}$ of $0.1 \mathrm{~N} \mathrm{HCl}$, maintained at a temperature of $36 \pm 0.5^{\circ} \mathrm{C}$. The agitation of the medium was maintained at $50 \mathrm{rpm} .10 \mathrm{ml}$ aliquots were withdrawn at $30 \mathrm{~min}$ interval up to $8 \mathrm{~h}$ and replaced each time with an equivalent of $10 \mathrm{ml}$ of the dissolution medium maintained at the same temperature. The withdrawn samples were filtered through a Whatman filter paper no.2, diluted appropriately and then analyzed spectrophotometrically at a wavelength of $271 \mathrm{~nm}$ using UNICOspectrophotometer (UV-2100PC Shanghai instrument Co. Ltd., China) and cumulative percentage drug release was calculated.

In vitro kinetic release studies of theophylline floating matrix tablets

Data obtained from dissolution studies were subjected to release kinetics evaluation to determine which model most appropriately describes it.

The model with the highest correlation coefficient $\left(R^{2}\right)$ was considered to be the best fit for the designated kinetic release.

\section{Mechanism of drug release from theophylline sustained release} matrix tablets

The likely mechanism of drug release was determined by plotting the percentage drug release fitted into Korsemeyer-Peppas model equation.

\section{Statistical analysis}

All experiments were carried out in triplicates and the results expressed as mean \pm SD. The data obtained were subjected to analysis of variance (ANOVA) and differences between means were considered significant at $\mathrm{P}<0.05$.

\begin{tabular}{|c|c|c|c|c|c|c|}
\hline $\begin{array}{l}\text { Formulation } \\
\text { code }\end{array}$ & $\begin{array}{l}\text { Bulk density } \\
(\mathrm{g} / \mathrm{ml}) \mathrm{n}=3\end{array}$ & $\begin{array}{l}\text { Tapped density } \\
(\mathrm{g} / \mathrm{ml}) \mathrm{n}=3\end{array}$ & $\begin{array}{l}\text { Carr's index (\%) } \\
n=3\end{array}$ & $\begin{array}{l}\text { Hausner's ratio } \\
\mathrm{n}=3\end{array}$ & $\begin{array}{l}\text { Angle of repose }\left({ }^{\circ}\right) \\
n=3\end{array}$ & $\begin{array}{l}\text { Flow rate } \\
(g / s) n=3\end{array}$ \\
\hline F1 & $0.34 \pm 0.00$ & $0.40 \pm 0.00$ & $14.51 \pm 0.26$ & $1.17 \pm 0.01$ & $30.40 \pm 1.31$ & $2.06 \pm 0.34$ \\
\hline $\mathrm{F} 2$ & $0.34 \pm 0.00$ & $0.40 \pm 0.01$ & $12.90 \pm 2.80$ & $1.16 \pm 0.00$ & $31.40 \pm 0.71$ & $3.03 \pm 0.38$ \\
\hline F3 & $0.30 \pm 0.00$ & $0.35 \pm 0.00$ & $15.47 \pm 0.39$ & $1.18 \pm 0.01$ & $28.00 \pm 0.90$ & $3.87 \pm 0.13$ \\
\hline
\end{tabular}

\section{RESULTS AND DISCUSSION}

Table 2: Micromeritic and flow properties of theophylline granules

KEY. Result is presented as mean \pm standard deviation and number of times $(n)=3$.

Table 3: Physical properties of theophylline floating tablet matrix

\begin{tabular}{lllllc}
\hline Batch code & $\begin{array}{l}\text { Weight (g) } \\
\mathbf{n = 2 0}\end{array}$ & $\begin{array}{l}\text { Thickness } \\
\text { (mm) } \mathbf{n = 1 0}\end{array}$ & $\begin{array}{l}\text { Diameter } \\
\text { (mm) } \mathbf{n = 1 0}\end{array}$ & $\begin{array}{l}\text { Hardness } \\
\text { (kg/f) } \mathbf{n = 1 0}\end{array}$ & $\begin{array}{l}\text { Friability } \\
\text { (\%) } \mathbf{n = 5}\end{array}$ \\
\hline F1 & $0.41 \pm 0.01(2.2 \%)$ & $3.14 \pm 0.11$ & $12.23 \pm 0.09$ & $4.34 \pm 0.32$ & 0.95 \\
F2 & $0.41 \pm 0.01(2.4 \%)$ & $3.13 \pm 0.04$ & $12.23 \pm 0.14$ & $4.44 \pm 0.32$ & 0.93 \\
F3 & $0.41 \pm 0.01(2.5 \%)$ & $3.23 \pm 0.08$ & $12.21 \pm 0.12$ & $4.52 \pm 0.31$ & 0.86 \\
\hline
\end{tabular}

Result is presented as mean \pm standard deviation and number of times $(n)=3$. 
Table 4: Other properties of theophylline granules and floating tablets

\begin{tabular}{lllll}
\hline Batch code & Granule density $(\mathrm{g} / \mathrm{ml})$ & Granule porosity $(\%)$ & Packing fraction & Tablet porosity (\%) \\
\hline F1 & $1.33 \pm 0.01$ & $74.30 \pm 0.01$ & $0.26 \pm 0.01$ & 58.20 \\
F2 & $1.28 \pm 0.01$ & $73.44 \pm 0.01$ & $0.27 \pm 0.01$ & 56.60 \\
F3 & $1.10 \pm 0.00$ & $72.70 \pm 0.00$ & $0.28 \pm 0.00$ & 51.10 \\
\hline
\end{tabular}

\section{Micromeritic and flow properties of theophylline granules}

The result of the micrometric and flow properties of granules is presented in table 2. From the result, there was an observed increase in the density from bulk density to tapped density. This results from the densification of the granules as a result of the tapping process. Tapping affects the packing of pharmaceutical powders and granules, causing a rearrangement in the bulk and leading to a reduction in the volume occupied by the granules/powder in the container [10]. Also, it was observed that the bulk and tapped densities decreased with an increase in polymer concentration. This observation is consistent with the formation of larger granules as the concentration of the polymer increases leading to larger voids in between larger granules. This is due to the increase in the formation of bonds between the theophylline particles and the polymer [11].

Hausner's ratio, angle of repose and Carr's index are indirect means of assessing the flow properties of granules. From the results obtained, the Carr's index ranged from $12.90 \%$ to $15.470 \%$, and Hausner's ratio ranged from 1.160 to 1.180 , indicating good flow property. The values for the angle of repose obtained were between $28.0^{\circ}$ to $31.4^{\circ}$ indicating flow property rated excellent to good [1]. Batch F1 and batch F3 with angle of repose values of $28.0^{\circ}$ and 30.4 $\circ$ respectively possessed excellent flow properties while batch F2 possessed good flow property.

The flow rate, a direct measure of assessing flow property, ranged from $2.06 \mathrm{~g} / \mathrm{s}$ to $3.87 \mathrm{~g} / \mathrm{s}$, with batch $\mathrm{F} 1$ possessing flow rate of 2.06 $\mathrm{g} / \mathrm{s}$ and batch F2 with a flow rate of $3.03 \mathrm{~g} / \mathrm{s}$ while batch F3 had a flow rate of $3.87 \mathrm{~g} / \mathrm{s}$. From the result, there was an observed increase in flow rate with an increase in polymer concentration. Increase in polymer concentration resulted in a significant difference $(\mathrm{p}<0.05)$ in the flow rate.

\section{Physical properties of theophylline floating tablet}

The result of the physical properties of tablets produced with the different proportions of HPMC is presented in the table 3. From the result, the crushing strength of the tablets was in the range of 4.34 to $4.52 \mathrm{~kg} / \mathrm{f}$, the weight variations of the tablets of all the formulation was less than $5 \%$. The friability of all the formulations was in the range of $0.86 \%$ to $0.95 \%$. Tablet thickness and diameter was in range of $3.13 \mathrm{~mm}$ to $3.23 \mathrm{~mm}$ and $12.21 \mathrm{~mm}$ to $12.23 \mathrm{~mm}$ respectively. Absolute drug content of all the formulations were found to be in range of $95.50 \%$ to $99.80 \%$. Floating lag time ranged from 52 seconds to 123 seconds. Total floating time was $>24 \mathrm{~h}$ for batch F1, F2 and F3.

Weight uniformity test is a pharmacopoeial test which ensures consistency of dosage units during compression. The weight uniformity test indicated no significant difference $(P>0.05)$ in the weights of tablets from batch F1 to F3 and hence conformed to the specification of the British Pharmacopoeia [12].

Although there was no significant difference $(p>0.05)$ amongst the tablet dimensions (thickness and diameter), tablet hardness was between $4.34 \mathrm{~kg} / \mathrm{f}$ and $4.54 \mathrm{~kg} / \mathrm{f}$ for all formulation. Tablet hardness affects parameters like tablet disintegration, dissolution as well as the buoyancy properties of the tablet [13]. There was no significant difference $(p>0.05)$ in the tablet hardness in the different proportions of the polymer used. However hardness exerts an effect on the floating of the tablets. This is because hardness influences the compaction of substances in the tablets, the higher the hardness, the higher the compaction. A higher compaction decreases the porosity of the tablet matrix causing a retardation of solvent penetration into the tablet core [15]. In fact Kiatissak et al., (2007) had reported that tablets with hardness of $8 \mathrm{~kg} / \mathrm{cm}^{2}$ showed no floating capability.
The friability of all the formulations was in the range of $0.86 \%$ to $0.96 \%$. The test of friability measures the ability of the tablet to withstand abrasion during packing, handling and shipping. The normal limits for tablet friability is less than or equal to $1 \%$ [12]. From the result of the study, the friability loss for all formulation was found to be within this stipulated limit. There was an observed decrease in tablet friability as the proportion of the polymer increases. The increased resistance of the matrices to fracture and abrasion as the polymer concentration increased could be attributed to the formation of more solid bonds [16].

The results of drug content for batch1, batch 2 and batch 3 were $99.50 \%, 98.80 \%$ and $99.8 \%$ respectively. These results are within the official limits [17], indicating proper mixing and processing of all the three batches.

\section{Other properties of theophylline granules and floating tablets}

The result of granule density, packing fraction, granule porosity and tablet porosity of theophylline floating tablets is shown in table 4 . From the result, the granule density ranged from $1.10 \mathrm{~g} / \mathrm{ml}$ to 1.33 $\mathrm{g} / \mathrm{ml}$, packing fraction ranged from 3.66 to 3.89 ; granule porosity is in the range of $72.70 \%$ to $74.30 \%$, while tablet porosity ranged from $51.10 \%$ to $58.20 \%$.

There was no significant difference $(p>0.05)$ in the granule density, granule porosity and packing fraction with an increase in polymer concentration. There was an observed decrease in porosity from granule to tablet; this is due to the compression of the granules during the tableting process which results in a reduction in porosity [18]. There was an observed increase in packing fraction with a decrease in granule porosity.

Porosity is a good predictor of how liquids enter into the tablet matrix; it also influences but not exclusively drug dissolution rate as other factors like solubility, surface area, particle size and polymer type play a role too [19]. There was no significant difference $(p>0.05)$ in the tablet porosity with increase in polymer concentration, however, there was a slight decrease in tablet porosity with increase in the polymer concentration. Spath et al., (2015) reported that an increase in binder concentration results in a reduction in tablet porosity as more of the inter particulate voids were filled with the binder/polymer solution. Tablets with low porosity retards the penetration of the medium into the tablet resulting in decrease drug release rate and prolong the floating lag time [19]. In this study, the tablet with the least porosity exhibited the shortest floating lag time. This may be due to the polymer content. It has been reported that unlike hydrophobic polymers such as ethylcellulose, in tablets formulated with hydrophilic polymers such as HPMC, tablet porosity may not be a critical factor for medium uptake by the tablet because of the polymers capability to absorb the test medium due to its hydrophilic property [21]. The swelling index study confirms this. Also in this study, a direct relationship was observed between tablet porosity and drug release rate, as the drug release rate decreases with a decrease in tablet porosity. Higher levels of polymer correspond to a lower porosity of the matrix tablet and a slower drug release rate can be achieved [22].

\section{Swelling index and in vitro buoyancy studies}

The swelling index study measures the hydration ability of the tablet. It influences tablet buoyancy, swelling behavior and drug release kinetics [23]. The result (fig. 3) shows that the swelling index increased with an increase in polymer concentration and contact time with the dissolution medium. The hydrophilic nature of the HPMC may have contributed to this observation with a sustained index after about 3hours likely signaling point of complete polymer hydration. From the result, the floating lag time ranges from 52 seconds to 123 seconds whereas the total floating time was $>24 \mathrm{~h}$ for each batch, and during this time, the size of the swollen matrix gel 
reduced because of disintegration and erosion. It was also observed that some of the gas generated from the tablet on hydration in the dissolution medium, was retained within the gel, thus decreasing the density of the tablet below $1.2 \mathrm{~g} / \mathrm{cm}^{3}$, and conferring buoyancy to the tablet. This was seen in tablets not disintegrating. Previous studies showed that tablets with a density greater than $1.004 \mathrm{~g} / \mathrm{cm}^{3}$ could not float on gastric fluid. A floating system is better with a shorter floating lag time (as seen in batch F3) so that the tablet may not attach to the lower part of the stomach impeding buoyancy, and suffering the physiological consequence of gastric emptying [1].

Table 5: Effect of HPMC concentration on the buoyancy property of the floating tablet

\begin{tabular}{lll}
\hline Batch code & Floating lag time (FLT) (s) $\mathbf{n}=\mathbf{3}$ & Total floating time (TFT) (h) \\
\hline F1 & $123 \pm 4.71$ & $>24$ \\
F2 & $77 \pm 4.98$ & $>24$ \\
F3 & $52 \pm 2.05$ & $>24$ \\
\hline
\end{tabular}

The increase in the concentration of the polymer did not have any significant effect $(\mathrm{p}>0.05)$ on the total floating time. However, the different proportions of the HPMC in the different batches had a significant effect $(\mathrm{p}<0.05)$ on the floating lag time as increased concentration of polymer resulted in decreased floating lag time. One possible reason could be related to the swelling index study, whereby the tablet with a higher proportion of the polymer

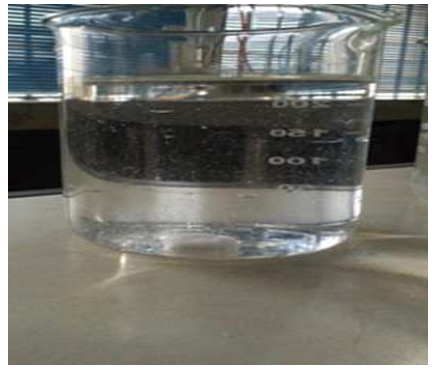

a. Tablet at initial time

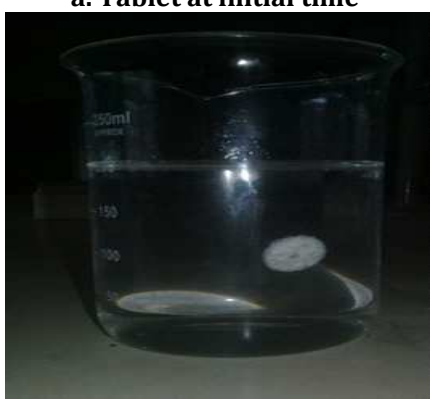

c. Tablet midway the medium exhibited more polymer hydration per time with the high swelling index value at any time compared to the tablet having lower polymer concentration. The rapid hydration of the polymer results in the formation of a gelatinous layer when in an aqueous medium. This gelatinous layer reduces the escape of generated gas from the tablet matrix thereby decreasing the density of the tablet which leads to the floating of the tablet within a short period of time [24].

Fig. 2: Photographs of in vitro floating behavior of theophylline floating tablet

\section{In vitro dissolution studies}

The release profile revealed that an increase in polymer concentration reduces the percentage of drug released. The increase in hydrophilic polymer proportion results in increase viscosity of the tablet matrix gel layer after hydration of the polymer as well as the formation of a gel layer with a longer diffusional path [25]. This phenomenon could explain the decrease in effective diffusion of the drug out of the gel and a consequent reduction in the rate of drug release.
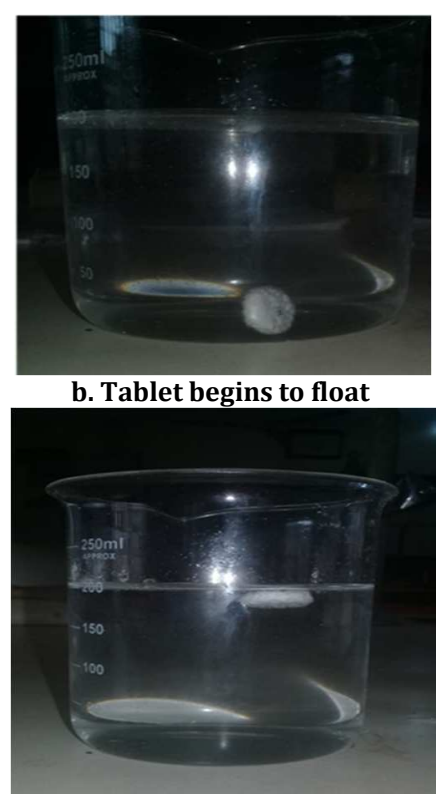

d. Tablet at the top of the medium
The percentage drug release at the end of $8 \mathrm{~h}$ was $100 \%, 98.2 \%$ and $96.13 \%$ for formulation batches F1, F2 and F3 respectively. The drug release was sustained for $8 \mathrm{~h}$ for all the batches.

However, there was an observed faster onset of drug release initially with a subsequent decrease in the release rate with time. Hydrophilicity of the polymer promotes the wetting of the tablet matrix with a burst release of the drug at the initial stage of hydration, then controlled release follows due to the viscous gel mass of the tablet polymer retarding drug release [24].

Table 6: Release kinetics of theophylline floating tablet

\begin{tabular}{|c|c|c|c|c|c|}
\hline \multirow[t]{2}{*}{ Batch code } & \multicolumn{4}{|c|}{$\mathbf{R}^{2}$} & \multirow[t]{2}{*}{ Diffusion exponent(n) } \\
\hline & Zero order & First order & Higuchi model & Korsemeyer model & \\
\hline F1 & 0.856 & 0.507 & 0.975 & 0.976 & 0.46 \\
\hline $\mathrm{F} 2$ & 0.864 & 0.278 & 0.973 & 0.975 & 0.51 \\
\hline F3 & 0.883 & 0.205 & 0.972 & 0.974 & 0.56 \\
\hline
\end{tabular}

Release kinetics and mechanism of release of theophylline floating tablets

The result of the in vitro release kinetics and mechanism of release of theophylline floating tablets is presented in table 6 . The regression values indicate that all the batches (F1, F2 and F3) followed Higuchi model of release kinetics. Thus the drug release is directly proportional to the square root of time, indicating that the drug release is diffusion controlled. Furthermore, the drug release data were fitted into the Korsemeyer-Peppas model (table 6) and it revealed that the diffusion 
mechanism involved in the drug release was non-Fickian diffusion type for F2 and F3 but fickian for F1. It has been reported that the release mechanism of drugs from HPMC matrix is by non-Fickian diffusion or anomalous transport involving both diffusion and matrix erosion [26]. Also, there was an observed increase in the value of the diffusion exponent (n) as the concentration of polymer increases.

\section{Release parameters of theophylline floating tablet}

The time is taken for $50 \%$ and $90 \%$ of theophylline to be released ( $t_{50}$ and $t_{90}$ ) respectively were adopted to characterize the release of theophylline from the tablets. From the result presented in table 7 , there was an observed increased in the time taken for $50 \%$ and 90 $\%$ of theophylline to be releasedwith an increased in the polymer concentration. At high polymer content, the gel layer becomes stronger and more viscous bringing about a higher resistance to diffusion and matrix erosion. This consequently retards drug release thus prolonging the time taken for $50 \%$ and $90 \%$ of the drug to be released respectively [25].

Also, higher polymer concentration increases the diffusion path length of the drug due to the formation of a greater amount of gel which retards drug release from the formulation.

Table 7: Release parameters of theophylline floating tablets

\begin{tabular}{lll}
\hline Batch code & $\mathbf{t}_{\mathbf{5 0}} \mathbf{( h )}$ & $\mathbf{t}_{\mathbf{9 0}} \mathbf{( h )}$ \\
\hline F1 & 1.9 & 5.6 \\
F2 & 2.2 & 6.0 \\
F3 & 2.5 & 6.2 \\
\hline
\end{tabular}

\section{CONCLUSION}

In conclusion, polymer concentration resulted in no significant difference ( $p>0.05)$ in granule density, granule porosity, packing fraction and tablet porosity. The increase in HPMC concentration from $15 \%$ to $30 \%$ did not have a significant effect ( $p>0.05)$ on the total floating time of the tablets as all tablet batches remained floated for more than $24 \mathrm{~h}$. However, the floating lag time (FLT) and swelling index were significantly affected $(\mathrm{p}<0.05)$ with higher HPMC concentration causing a reduction in the floating lag time but an increase in the swelling index of the tablet. An increase in the polymer concentration reduced drug release rate and followed the Higuchi model. While Batches F2 and F3 followed non Fikian mechanism of release, F1 was in line with the Fikian type. Finally, Batch F3, containing $30 \%$ of HPMC gave the best drug delivery and floating properties in comparison to the other batches, as it possessed the shortest floating lag time as well as gave a better control of the rate of drug release.

\section{AUTHORS CONTRIBUTIONS}

Akpabio E designed the work, supervised Sunday N to carry out the laboratory work with guidance from Uwah T. Effiong D wrote the article. All authors critically revised and approved the work for publication.

\section{FUNDING}

Nil

\section{CONFLICT OF INTERESTS}

None

\section{REFERENCES}

1. Aulton ME, Kelvin TMG. Aulton's pharmaceutics: the design and manufacture of medicines (4th ed.) Churchill Livingstone Elsevier; 2013. p. 30-61.

2. Bijumol C, Helen W, Jose $\mathrm{K}$, Thomas K. Formulation and evaluation of floating tablets of theophylline. Hygeia J D Med 2013;5:23-31.

3. Nayak K, Ruma M, Biswarup D. Gastroretentive drug delivery systems: a review. Asian J Pharm Clin Res 2010;3:1-10.

4. Arora S, Javed A, Alka A, Roop K, Sanjula B. Floating drug delivery systems: a review. AAPS PharmSciTech 2005;6:37290.

5. Nanda A, Chugh C. Gastroretentive drug delivery systems: a review. Int J Pharm Bio Sci 2017;8:62-8.

6. Aitipamula S, Wong BH, Kanaujia P. Evaluating suspension formulations of theophylline cocrystals with artificial sweeteners. J Pharm Sci 2018;107:604-11.

7. Riahi S, Mousavi MF. A novel potentiometric sensor for selective determination of theophylline: theoretical and practical investigations. Anal Chem Acta 2005;548:192-8.
8. Kendre PN, Lateef SN, Godge RK, Chaudhari PD, Fernandes SL, Vibhute SK. Oral sustained delivery of theophylline floating matrix tablets-formulation and in vitro evaluation. Int J PharmTech Res 2010;2:130-9.

9. Srikanth Meka V, Ee Li C, Sheshala R. Design and statistical optimization of an effervescent floating drug delivery system of theophylline using response surface methodology. Acta Pharm 2016;66:35-51.

10. Ofoefule SI, Chukwu A. Binding property of Treculia africana gum in sodium salicylate tablets. STP Pharma Sci 1994;4:394-8.

11. Rakhi B, Shah, Tawakul MA, Khan MA. Comparative evaluation of flow for pharmaceutical powders and granules. AAPS PharmSciTech 2008;9:250-8.

12. British Pharmacopoeia. Pharmaceutical Press, Cambridge, London; 2008.

13. Quereshi J, Ijaz H, Sethi A, Zaman M, Bashir I, Hanif M, et al. Formulation and in vitro evaluation of sustained release matrix tablets of metoprolol tartrate using synthetic and natural polymers. Lat Am J Pharm 2014;33:1533-9.

14. Kiattisak S, Yanee P, Helmet V, Siripon O. Factors influencing drug dissolution characteristics from hydrophilic polymer matrix tablet. Sci Pharm 2007;75:147-64.

15. Nur AO, Zhang JS. Captopril floating and/or bioadhesive tablets: design and release kinetics. Drug Dev Ind Pharm 2000;26:965-9.

16. Alderborn G, Nystrom C. Studies on direct compression of tablets XIV: the effect of powder fineness on the relation between tablets permeametry surface and compaction pressure. Powder Technol 1985;44:37-42.

17. USP28. The United States Pharmacopeia 28: The National Formulary 23. United States Pharmacopeial Convention; 2004.

18. Juppo AM, Yliruusi J. Effect of amount of granulation liquid on total pore volume and pore size distribution of Lactose, glucose and mannitol granule. Eur J Pharm Bio Pharm 1994;40:299309.

19. Yassin S, Goodwin DJ, Zeitler AJ. The disintegration process in microcrystalline S cellulose-based tablet; the influence of temperature, porosity and superdisintegrants. J Pharm Sci 2015;104:76-93.

20. Spath S, Drescher P, Herman H. Impact of particle size of ceramic blends on mechanical strength and porosity of 3D printed scaffolds. Material 2015;8:4720-32.

21. Jeong SH, Thapa P. Effects of formulation and process variables on gastroretentive floating tablets with a high dose soluble drug and experimental design approach. Pharmaceutics 2018;10:1-25.

22. Reza MS, Quadir MA, Haider SS. Comparative evaluation of rate of hydration and matrix erosion of HEC and HPC and study of drug release from their matrices. Eur J Pharm Sci 2003;16:193-9.

23. Wan SC, Heng WS, Wong LP. Relationship between swelling and drug release in the hydrophilic matrix. Drug Dev Ind Pharm 1993;19:1201-10. 
24. Venkateswarlu K, Preethi KJ, Kiran BS. Formulation development and in vitro evaluation of floating tablets of ciprofloxacin HCL. Asian J Pharm 2016;10:271-8.

25. Gunjal PT, Gharge VS, Pimple SV, Gurjar MK, Shah MN. Design, development and optimization of $S$ (-) atenolol floating sustained release matrix tablets using surface response method. Ind J Pharm Sci 2015;77:565-72.

26. Conti S, Maggi L, Segale L, Machiste EO, Conte U, Grenier P, Vergnault G. Matrices containing NaCMC and HPMC: I. Dissolution performance characterization. Int J Pharm 2007;333:136-42. 